\title{
Study of white matter integrity in fathers of children with attention deficit hyperactivity disorder
}

\author{
Heba H. ElShahawi ${ }^{1}$, Safeya M. Effat ${ }^{1}$, Eman M. Shorab ${ }^{1}$, Hossam M. Sakr ${ }^{2}$, Safaa E. Azab ${ }^{1}$ and Ola M. Aufa ${ }^{*^{*}}$ (I)
}

\begin{abstract}
Background: Attention deficit hyperactivity disorder (ADHD) is an early-onset neurodevelopmental disorder that can extend into adulthood with multiple reported neuroimaging abnormalities. The focus of this research was to assess white matter impairments in ADHD children's fathers with and without potential adult ADHD to see if these differences are connected with the persistence of ADHD into adulthood.

Results: The occurrence rate of the potential adult ADHD diagnosis among fathers of children with ADHD was $60 \%$. There were statistically significant differences between fathers with ADHD and the non-ADHD population, due to the fact that the mean FA of the left superior corona radiata and the right posterior corona radiata were lower in the ADHD group than in the non-ADHD group, while the FA of the ADHD group was significantly greater than that of the non-ADHD group in terms of the left and right anterior thalamic radiations, the right superior longitudinal fasciculus and the left anterior corona radiata.

Conclusions: We observed an increased prevalence of ADHD in fathers of children diagnosed with ADHD. Fathers with potential adult ADHD have a variety of white matter abnormalities that reflect the neurobiological basis of $A D H D$, even in sub-threshold cases. This may provide insight into the neuroanatomical locations associated with the maintenance of ADHD throughout adulthood.
\end{abstract}

Keywords: ADHD, DTI, White matter, Adult ADHD

\section{Background}

Around $7.2 \%$ of children and adolescents and $2.5 \%$ of adults have ADHD [1, 2]. The incidence of persistent ADHD symptoms in adulthood varies considerably, ranging from 78 [3] to $40 \%$ [4].

Instead of focusing on regional impairments, neuroimaging studies in ADHD have turned toward a connectivity strategy that studies the functional and anatomical association between brain regions. With this perspective, the pathophysiology of ADHD is viewed from the perspective of organizational dysfunctions of the distributed

\footnotetext{
* Correspondence: olaaufa@gmail.com

${ }^{1}$ Department of Psychiatry, Faculty of Medicine, Ain Shams University, No. 38 Abbaseya St., Cairo Postal code 11517, Egypt

Full list of author information is available at the end of the article
}

network rather than local functional and structural impairments [5].

Diffusion tensor imaging (DTI) is an approach that is equivalent to magnetic resonance imaging (MRI) that can be utilized to detect white matter (WM) pathways by providing information about the diffusion of water molecules. The fractional anisotropy (FA) is the most critical index derived from the DTI study. FA is highest in compact and well-myelinated fibers, whereas low FA is related to WM degradation [6].

DTI research in ADHD has accelerated in the recent decade, enabling in vivo investigation of the microstructural preservation of WM tracts [5].

The few DTI studies available in adult ADHD patients have shown a decrease in FA in signaling pathways such as the cingulate tract [7], the inferior longitudinal

\section{Springer Open}

(c) The Author(s). 2021 Open Access This article is licensed under a Creative Commons Attribution 4.0 International License, which permits use, sharing, adaptation, distribution and reproduction in any medium or format, as long as you give appropriate credit to the original author(s) and the source, provide a link to the Creative Commons licence, and indicate if changes were made. The images or other third party material in this article are included in the article's Creative Commons licence, unless indicated otherwise in a credit line to the material. If material is not included in the article's Creative Commons licence and your intended use is not permitted by statutory regulation or exceeds the permitted use, you will need to obtain permission directly from the copyright holder. To view a copy of this licence, visit http://creativecommons.org/licenses/by/4.0/. 
fasciculus (ILF) [8], the superior longitudinal fasciculus (SLF) $[7,9]$, and the corpus callosum [10].

Although there is evidence of decreased FA in ADHD individuals, there is also evidence of elevated FA [1113]. Additionally, Tamm et al. 2012 [14] demonstrated that FA levels were found to be considerably greater in ADHD in various white matter pathways, such as anterior forceps, the anterior corona radiata, inferior frontooccipital fasciculus, and anterior thalamic radiations.

Although there are no longitudinal DTI studies in the current ADHD literature, FA levels were observed to be significantly decreased in recurrent and remitted individuals with ADHD compared to normal controls. The corona radiata, superior longitudinal fasciculus, sagittal stratum, and retrolenticular internal capsule consistently exhibit these persistent outcomes [9].

The focus of this research was to evaluate the white matter features of children's fathers with and without expected ADHD in adulthood that may correlate to the maintenance of ADHD throughout adulthood.

\section{Methods}

\section{Study design and participants}

This was an observational comparative cross-sectional study. A suitable sample of children associated with ADHD was drawn from the child outpatient clinics of the Institute of Psychiatry Ain Shams University in Cairo, Egypt, which are localized in the eastern part of the city and serve roughly a third of bigger Cairo's population.

The research study enrolled 100 children associated with ADHD between the ages of 6 and 12 years, as well as their biological fathers, who fulfilled the DSM-IV criteria for ADHD. A higher occurrence rate of ADHD symptoms in fathers is to be expected since a high paternal transmission has been approved compared to maternal transmission indicating genomic imprinting [15].

Fathers were excluded if they would have an axis I psychiatric issue, a chronic health disease, or DSM-IV-TR substance addiction (excluded for nicotine consumption), or if they had any adverse side effects to MRI (for example, metal implants, cardiac pacemaker, or aneurysm coiling), or if the father refused to sign consent.

\section{Procedure}

Children with ADHD had the following tests: The Kiddies schedule for Affective Disorders and Schizophrenia present and Lifetime [16] to evaluate children with ADHD. The severity and type of ADHD were confirmed by Conner's parent rating scale—-revised; long version (CPRS-L) [17].

Fathers who participated in the study done the entire questionnaires
1- Ain Shams University's Okasha Institute of Psychiatry's psychiatric sheet: Personally identifiable information, current psychiatric disorder, prior psychiatric history, family history of psychiatric conditions, concomitant health issues, and concomitant therapies are all evaluated.

2- SCID-I, the structured clinical interview for DSMIV axis I disorder has been utilized to diagnose any co-morbid psychiatric disorder [18].

3- The Conners' adult ADHD rating scale self-report: long version (CAARS-S: L) [19] is a multimodal evaluation tool for adults with ADHD symptoms and behaviors. We used the self-assessment version of this tool which has 66 items.

4- Tractography using diffusion tensor imaging (DTI): All children's fathers were examined utilizing a 1.ST scanner (Achiva Philips). The signal strength was received using an S-channel head coil. The diffusion-weighted spin-echo EPI sequence used in the DTI was a single-shot diffusion-weighted spinecho sequence (TR/TE, 8000/68.7 ms; parallel imaging [array special sensitivity encoding technique] with a factor of two; matrix, $80 \times 78$; FOV, $22 \mathrm{~cm}$; section thickness, $2 \mathrm{~mm}$; 50 continuous sections).

\section{Statistical analysis}

Offline processing and analysis of DTI data were conducted. The data has been loaded into the software package so that we select the regions of interest. Regions of interests (ROIs) were placed over the presumed anatomical regions. Tractography was performed to isolate the suspected tracts based on a specific ROI for each tract bilaterally (anterior corona radiate $(\mathrm{ACR})$, posterior corona radiate (PCR), superior corona radiata, superior longitudinal fasciculus (SLF), middle cerebellar peduncle $(\mathrm{MCP})$, anterior thalamic radiation (ATR)). Fractional anisotropy was the parameter used to compare between groups. FA denotes the ratio of parallel to axon water diffusion to perpendicular to axon water diffusion. It is the most frequently utilized index, reflecting fiber tracts' directional and continuous nature [20].

The statistical tool SPSS (Statistical Package for the Social Sciences) version 25 was used to organize and enter the data. In quantitative data, the mean, standard deviation, median, minimum, and maximum were calculated; in categorical data, the frequency (count) and relative frequency (\%) were calculated. The Kruskal-Wallis and Mann-Whitney tests were used to make nonparametric comparisons between numerical variables. To evaluate categorical data, the chi-square $\left(\mathrm{c}^{2}\right)$ test was used. When the predicted probability is less than 5 , an appropriate test was employed. $P$ values (less than 0.05 ) indicates a significant difference. 


\section{Results}

Participants' socio-demographic and clinical features

The present study recruited 100 children with ADHD and their biological fathers. Regarding children, their mean age was $9.8(+1.6)$, $95 \%$ were males, the majority (75\%) attended public school, $80 \%$ were already taking medication, and the majority had mixed types of ADHD (85\%). Concerning fathers, their mean age was 44.3 $(+5.78)$ years, only $20 \%$ received high education, another $20 \%$ received primary education, and the remaining $60 \%$ received secondary education. Most of them (85.0\%) were married and employed (85.0\%).

\section{The prevalence of adult ADHD in fathers}

When fathers were rated on the Conners' Adult ADHD rating scale, $60 \%$ of them had potential adult ADHD (50\% of them had mixed inattentive-hyperactive type, $25 \%$ inattentive type, and $25 \%$ hyperactive-impulsive type) (Table 1).

\section{Comparison between fathers with potential adult ADHD} and fathers without as regards age and educational level There were no statistically significant variances in age or educational level between fathers with and without potential adult ADHD.

\section{Comparison between fathers with potential adult ADHD} and fathers without as regards results of diffusion tensor imaging (Table 2) "shown in Fig. 1"

There were statistically significant variances between the ADHD group of fathers and the non-ADHD group, as the ADHD group's mean FA of right PCR and left SCR was lower than the non-ADHD group's. While we observed a statistically significant increase in the FA of bilateral ATR, bilateral ACR, and right SLF in ADHD fathers compared to non-ADHD fathers.

\section{Discussion}

This research is noteworthy because of the assumption that the behavioral and the cognitive elements of ADHD are quite well recognized. However, the ADHD neurobiological substance must be studied. Therefore, the

Table 1 According to Conners' adult ADHD rating scale, the prevalence and type of ADHD in fathers

\begin{tabular}{llll}
\hline & & Count & $\%$ \\
\hline ADHD (fathers) & No ADHD & 40 & $40 \%$ \\
& ADHD & 60 & $60 \%$ \\
Type of ADHD (fathers) & 5- Inattentive & 15 & $25 \%$ \\
& 6- Hyperactive & 15 & $25 \%$ \\
& 7- Combined & 30 & $50 \%$ \\
\hline
\end{tabular}

populations studied were fathers with potential ADHD who did not seek medical advice and were functioning; this enabled us to study brain structural abnormalities which could play an essential role in ADHD pathophysiology. These areas might serve as a trait marker for adult ADHD, or could be anatomical sites for the persistence of ADHD into adulthood.

Gray matter assessment studies in ADHD showed cortical abnormalities and maturation delays in certain prefrontal cortex areas in individuals with ADHD [21]. However, the significance of aberrant white matter (WM) advancement in ADHD remains relatively obscure [5]. Although in ADHD individuals, the volume decreases recorded in WM are larger than that in a gray matter [22].

The present study showed that $60 \%$ of fathers of children were diagnosed with potential adult ADHD using Conners' adult ADHD rating scale $(50 \%$ of them had mixed inattentive-hyperactive type-25\% predominantly, inattentive type-25\% predominantly, hyperactive-impulsive type) (Table 1). However, none of the fathers with potential adult ADHD sought medical advice or received treatment. This may be related to the nature of their occupation and the fact that $80 \%$ did not receive a college education. Currently, the incidence of ADHD among paternal adults is $60 \%$, which corresponds to the findings of Smalley et al. and Starck et al. [23, 24], who reported that the adult ADHD prevalence rate among fathers of ADHD children was $55 \%$ and $56 \%$ respectively. On the contrary, several studies $[15,25,26]$ showed that ADHD in fathers was $41 \%, 45.8 \%$, and $2.6 \%$, respectively. These findings could be attributed to various diagnostic procedures, information sources, and social and cultural characteristics (sex, ethnicity, population type, residence place, socioeconomic level, and sample type). However, the occurrence of this variable remains high. Therefore, screening for paternal ADHD is important to be integrated into clinical settings, as this affects family function, child therapy outcome, and family therapy as well [27].

Regarding the white matter abnormalities findings, there were marked differences in DTI results between fathers with and without potential adult ADHD with a statistically significant decreased mean FA of right PCR and left SCR in the ADHD group suggesting the presence of deficits in those areas. It is well-known that these areas support the cognitive and perception part of the motor cortex [28].

The few available studies on the results of DTI in patients with ADHD have shown quite heterogeneous results. The comparability of ROI experiments can be reduced, considering the subjective recruitment and selection process of ROIs [5]. 
Table 2 Comparison between fathers with the diagnosis of potential adult ADHD vs. those without potential adult ADHD as regards to findings of DTI

\begin{tabular}{|c|c|c|c|c|c|c|c|c|}
\hline \multirow{3}{*}{$\begin{array}{l}\text { Diffusion tensor imaging (DTI) } \\
\text { Fractional anisotropy (FA) }\end{array}$} & \multicolumn{6}{|c|}{ All fathers $(n=100)$} & \multirow[t]{3}{*}{ Test } & \multirow[t]{3}{*}{$P$ value } \\
\hline & \multicolumn{3}{|c|}{ ADHD fathers $(n=60)$} & \multicolumn{3}{|c|}{ Non ADHD fathers $(n=40)$} & & \\
\hline & Average mean & SD & Median & Mean & SD & Median & & \\
\hline Right anterior corona radiata & .35 & .05 & .34 & .34 & .13 & .38 & 2.472 & $0.013^{*}$ \\
\hline Left anterior corona radiata & .37 & .02 & .38 & .29 & .12 & .34 & 4.411 & $<0.001^{* *}$ \\
\hline Right anterior thalamic radiation & .48 & .05 & .48 & .40 & .16 & .43 & 3.175 & $<0.001 * *$ \\
\hline Left anterior thalamic radiation & .50 & .03 & .51 & .39 & .15 & .43 & 7.055 & $<0.001 * *$ \\
\hline Right superior longitudinal fasciculus & .44 & .04 & .45 & .43 & .04 & .41 & 2.646 & $<0.008 *$ \\
\hline Left superior longitudinal fasiculus & .49 & .02 & .49 & .50 & .04 & .51 & 1.411 & 0.158 \\
\hline Right posterior corona radiata & .41 & .06 & .40 & .44 & .06 & .47 & 3.970 & $<0.001$ \\
\hline Left posterior corona radiata & .43 & .06 & .42 & .42 & .08 & .42 & .265 & 0.791 \\
\hline Right middle cerebellar peduncle & .46 & .09 & .45 & .45 & .07 & .45 & 1.058 & 0.290 \\
\hline Left middle cerebellar peduncle & .48 & .07 & .49 & .48 & .06 & .45 & .882 & 0.378 \\
\hline Right superior corona radiata & .46 & .03 & .46 & .45 & .02 & .46 & 1.587 & 0.112 \\
\hline Left superior corona radiata & .45 & .03 & .45 & .49 & .03 & .48 & 5.115 & $<0.001$ \\
\hline
\end{tabular}

Non-parametric Mann-Whitney test

${ }^{*} P$ value less than 0.05 is considered significant

**P value less than 0.001 is considered highly significant

$P$ value greater than 0.05 is considered non-significant

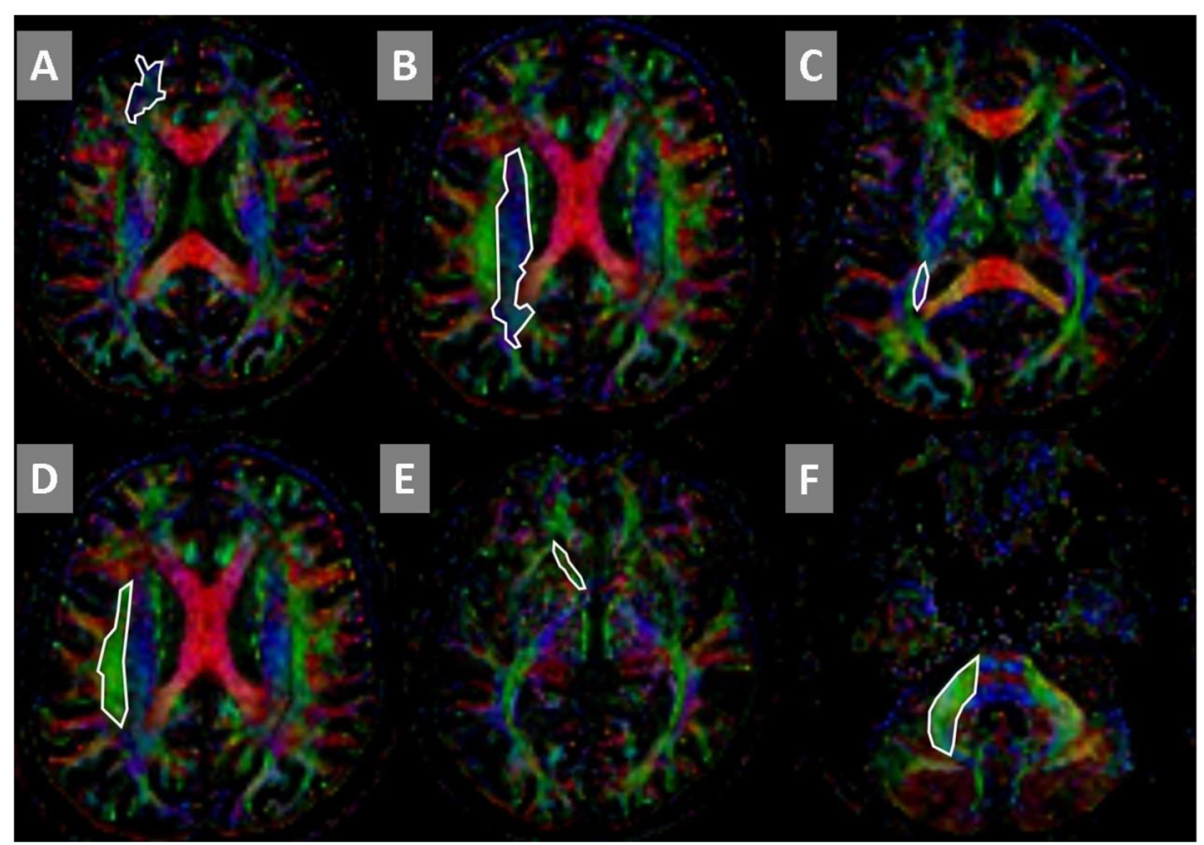

Fig. 1 Axial color map images with a drawing showing ROls used for different tracts. (A) anterior corona radiata, (B) superior corona radiata, (C) posterior corona radiate, (D) superior longitudinal fasciculus, (E) anterior thalamic radiation, (F) middle cerebellar peduncle 
Our results partially reproduce those of Bouzianea et al. [29] who found reduced FA in the anterior and superior areas of $\mathrm{CR}$ in the adult ADHD group without previous medication treatment. The decreased FA agrees with multiple previous studies in adult ADHD $[9,10,30]$.

The reduced FA may be a persistent indication of whether or not individuals have ADHD symptoms in adulthood with ADHD [9].

Interestingly, we found a statistically higher FA of bilateral ACR, bilateral ATR, and right SLF in the ADHD group of fathers than the non-ADHD group.

Although ADHD mostly had decreased FA, there are also signs that the greater FA of some tracts of white matter is in keeping with our findings [11-13]. Additionally, Tamm et al. [14] observed an elevation in FA in the ACR, anterior forceps, uncinate fasciculus, inferior fronto-occipital fasciculus, and ATR in individuals with ADHD.

We can explain this finding with the following possibilities: Firstly, high FA reflects a high directed diffusion consistency, and is linked to the reduced neuronal branching in individuals [5]. Secondly, this finding could reflect the compensatory mechanisms similar to those observed in patients with a stroke who exhibited enhanced FA in axonal regeneration or chronic remyelination and healing-related gliosis [30]. Thirdly, one study indicated that enhanced FA in children and teens with ADHD is attributable to higher axial and less radial diffusivity in the WM pathways, demonstrating relative axonal integrity in these locations, but a reduction in neuronal branching [11].

Additional research is required to contrast the findings of white matter abnormalities with genetic evidence regarding the pathophysiology of ADHD persistence into adulthood [31].

Previous results of FA in parents with potential adult ADHD may point to areas involved in the pathogenesis and genetics of ADHD.

\section{Conclusions}

Our study's findings indicated a high frequency of ADHD in fathers of ADHD-related children. In fathers of children with ADHD, there have been varying alterations in WM, either in the manner of reduced or elevated FA of various white matter tracts, which may have an etiopathogenic impact on the maintenance of ADHD into adulthood.

\section{Limitations}

When interpreting the results, there are some important points to consider: First, the limited sample size may restrict the generalizability of these findings, making it critical to replicate the work on a larger group of individuals to determine the importance of specific findings.
Second, fathers were diagnosed as potential adult ADHD according to CAARs. Furthermore, we need a whole white matter assessment to reach a full conclusion about the white matter changes in this group. Additionally, we must establish a correlation between these alterations and the clinical and cognitive phenotypes of ADHD.

\section{Abbreviations \\ ADHD: Attention deficit hyperactivity disorder; ATR: Anterior thalamic radiation; CAARS-S: L: Conners' adult ADHD rating scale self-report: long ver- sion; CPRS-L: Conners' parent rating scale; DSM IV: Diagnostic and statistical manual IV; DTI: Diffusion tensor image; FA: Fractional anisotropy; ILF: Inferior longitudinal fasciculus; MRI: Magnetic resonance image; PCR: Posterior corona radiata; ROIS: Regions of interest; SCID I: Structured clinical interview for DSM IV axis I disorders; SCR: Superior corona radiata; SLF: Superior longitudinal fasciculus; SPSS: Statistical Package for the Social Science; WM: White matter}

\section{Acknowledgements}

"Not applicable"

\section{Authors' contributions}

H. E.: study idea and design, data analysis and interpretation, and manuscript critical revision. S. E.: study idea and design, data analysis and interpretation, and manuscript critical revision. $\mathrm{H}$. S. gave significant contributions to the conceptualization and design of the present research, as well as to the analysis of DTI data. E. S. developed the study idea and design, analyzed and interpreted the data, and revised the manuscript critically. O. A.: data analysis and interpretation, as well as manuscript writing and editing. S. A. enrolled, evaluated, and obtained all data on the individuals. The final manuscript was read and approved by all authors.

\section{Funding}

This research received no specific support from the public, commercial, or not-for-profit funding organizations.

Availability of data and materials

The data underpinning this article will be provided with the corresponding author upon causative request.

\section{Declarations}

Ethics approval and consent to participate

Before each parent participated in the study, the study's nature was communicated with them, and informed consent was taken and collected from each parent. The Ain Shams University Hospital Ethics Committee authorized this study after a very clear statement that provided information on the following points; study rationale, involvement in this experiment was entirely voluntary, and there was no direct advantage to him as a result of his involvement, but the information gathered could be utilized to assist other individuals. They may be revoked at any moment without explanation and without compromising their child care service, and the study's findings may be published in scholarly journals. However, the patients' and fathers' identities would remain absolutely anonymous.

Committee reference number: 1936/2014

\section{Consent for publication}

"Not applicable"

\section{Competing interests}

The authors declare that they have no competing interests.

\section{Author details}

${ }^{1}$ Department of Psychiatry, Faculty of Medicine, Ain Shams University, No. 38 Abbaseya St., Cairo Postal code 11517, Egypt. ²Department of Radiology, Ain Shams University, Cairo, Egypt. 
Received: 15 July 2021 Accepted: 19 August 2021

Published online: 05 October 2021

\section{References}

1. Katzman MA, Bilkey TS, Chokka PR, Fallu A, Klassen LJ (2017) Adult ADHD and co-morbid disorders: clinical implications of a dimensional approach. BMC Psychiatry 17(1):302. https://doi.org/10.1186/s12888-017-1463-3

2. Thomas R, Sanders S, Doust J, Beller E, Glasziou P (2015) Prevalence of attention-deficit/hyperactivity disorder: a systematic review and metaanalysis. Pediatrics. 135(4):994-1001

3. Biederman J, Petty CR, Clarke A, Lomedico A, Faraone SV (2011) Predictors of persistent ADHD: an 11-year follow-up study. J Psychiatr Res 45(2):150155. https://doi.org/10.1016/j.jpsychires.2010.06.009

4. Kessler RC, Adler LA, Barkley R, Biederman J, Conners CK, Faraone SV, Greenhill LL, Jaeger S, Secnik K, Spencer T, Üstün TB, Zaslavsky AM (2005) Patterns and predictors of attention-deficit/ hyperactivity disorder persistence into adulthood: results from the national comorbidity survey replication. Biol Psychiatry 57(11):1442-1451. https://doi.org/10.1016/j. biopsych.2005.04.001

5. Ewijka H, Heslenfeld DJ, Zwiers MP, Buitelaar JK, Oosterlaan J (2012) Diffusion tensor imaging in attention-deficit/hyperactivity disorder: a systematic review and meta-analysis. Neurosci Biobehav Rev 36(4):10931106. https://doi.org/10.1016/j.neubiorev.2012.01.003

6. Bode MK, Lindholm P, Kiviniemi V, Moilanen I, Ebeling H, Veijola J, Miettunen J, Hurtig T, Nordström T, Starck T, Remes J, Tervonen O, Nikkinen J (2015) DTI abnormalities in adults with a history of attention deficit hyperactivity disorder: a tract-based spatial statistics study. Acta Radiol 56(8): 990-996. https://doi.org/10.1177/0284185114545147

7. Makris N, Buka SL, Biederman J, Papadimitriou GM, Hodge SM, Valera EM, Brown AB, Bush G, Monuteaux MC, Caviness VS, Kennedy DN, Seidman LJ (2008) Attention and executive systems abnormalities in adults with childhood ADHD: a DT-MRI study of connections. Cereb Cortex 18(5):12101122. https://doi.org/10.1093/cercor/bhm156

8. Konrad A, Dielentheis TF, El Masri D et al (2012) White matter abnormalities and their impact on attentional performance in adult attention-deficit/ hyperactivity disorder. Eur Arch Psychiatry Clin Neurosci 262(4):351-336. https://doi.org/10.1007/s00406-011-0251-1

9. Cortese S, Imperati D, Zhou J, Proal E, Klein RG, Mannuzza S, RamosOlazagasti MA, Milham MP, Kelly C, Castellanos FX (2013) White matter alterations at 33-year follow-up in adults with childhood attention-deficit/ hyperactivity disorder. Biol Psychiatry 74(8):591-598. https://doi.org/10.1016/ j.biopsych.2013.02.025

10. Dramsdahl M, Westerhausen R, Haavik J, Hugdahl K, Plessen KJ (2012) Adults with attention-deficit/hyperactivity disorder - a diffusion-tensor imaging study of the corpus callosum. Psychiatry Res 201(2):168-173. https://doi. org/10.1016/j.pscychresns.2011.08.005

11. Silk TJ, Vance A, Rinehart N, Bradshaw JL, Cunnington R (2009) White-matter abnormalities in attention deficit hyperactivity disorder: a diffusion tensor imaging study. Hum Brain Mapp 30(9):2757-2765. https://doi.org/10.1002/ hbm.20703

12. Kobel M, Bechtel N, Specht K, Klarhöfer M, Weber P, Scheffler K, Opwis K, Penner IK (2010) Structural and functional imaging approaches in attentiondeficit/hyperactivity disorder: does the temporal lobe play a key role? Psychiatry Res 183(3):230-236. https://doi.org/10.1016/j.pscychresns.2010.03.010

13. Peterson DJ, Ryan M, Rimrodt SL, Cutting LE, Denckla MB, Kaufmann WE, Mahone EM (2011) Increased regional fractional anisotropy in highly screened attention-deficit hyperactivity disorder (ADHD). J Child Neurol 26(10):1296-1302. https://doi.org/10.1177/0883073811405662

14. Tamm L, Goraly BN, Reiss AL (2012) Diffusion tensor imaging reveals white matter abnormalities in attention-deficit/ hyperactivity disorder. Psychiatry Res 202(2):150-154. https://doi.org/10.1016/j.pscychresns.2012.04.001

15. Goos LM, Ezzatian P, Schachar R (2007) Parent-of-origin effects in attentiondeficit hyperactivity disorder. Psychiatry Res 1(49):1-9

16. Kaufman J, Birmaher B, Brent D et al (1997) Schedule for affective disorders and schizophrenia for school-age children-present and lifetime version (KSADS-PL): initial reliability and validity data. J Am Acad Child Adolesc Psychiatry 36(7):980-988. https://doi.org/10.1097/00004583-199707000-00021

17. Conners CK (1997) Conners' rating scales-revised. User's manual. MultiHealth Systems Inc, North Tonawanda, p 1997

18. First MB, Spitzer RL, Gibbon M, Williams JB (1996) Structured clinical interview for DSM IV axis I disorders
19. Conners CK, Erhardt D, Sparrows E (1999) Conners adult ADHD rating scales (CAARS). Multi-Health Systems, Inc., North Tonawanda

20. Madden DJ, Bennett IJ, Burzynska A, Potter GG, Chen NK, Song AW (2012) Diffusion tensor imaging of cerebral white matter integrity in cognitive aging. Biochim Biophys Acta Mol basis Dis 18(22):386-400

21. Shaw P, Eckstrand K, Sharp W et al (2007) Attention-deficit/hyperactivity disorder is characterized by a delay in cortical maturation. Proc Natl Acad Sci U S A 104:19649-19654

22. Castellanos FX, Lee PP, Sharp W, Jeffries NO, Greenstein DK, Clasen LS, Blumenthal JD, James RS, Ebens CL, Walter JM, Zijdenbos A, Evans AC, Giedd JN, Rapoport JL (2002) Developmental trajectories of brain volume abnormalities in children and adolescents with attention-deficit/ hyperactivity disorder. J Am Med Assoc 288(14):1740-1748. https://doi.org/1 0.1001/jama.288.14.1740

23. Smalley SL, MCGough JJ, Del'Homme M et al (2000) Familial clustering of symptoms and disruptive behaviors in multiplex families with attentiondeficit/hyperactivity disorder. J Am Acad Child Adolesc Psychiatry 39(9): 1135-1143. https://doi.org/10.1097/00004583-200009000-00013

24. Starck M, Grünwald J, Schlarb A (2016) The occurrence of ADHD in parents of ADHD children in a clinical sample. Neuropsychiatr Dis Treat 12:581-588. https://doi.org/10.2147/NDT.S100238

25. Ghanizadeh A, Mohammadi MR, Moini R (2008) Comorbidity of psychiatric disorders and parental psychiatric disorders in a sample of Iranian children with ADHD. J Atten Disord 12(2):149-155. https://doi.org/10.1177/1087054 708314601

26. Meerbeke AV, Gutiérrez TC, Miramón Zl, Guzmán-Ramírez GM (2017) Attention deficit hyperactivity disorder: from parents to children. Neurologia. 32(3):158-165

27. Tuscano CA, Stein MA (2012) Pharmacotherapy for parents with attentiondeficit hyperactivity disorder (ADHD): impact on maternal ADHD and parenting. CNS Drugs 26(9):725-732. https://doi.org/10.2165/11633910000000000-00000

28. Gage N, Baars B (2012) Fundamental of Cognitive neuroscience a beginner's guide, 2nd edn. Academic Press

29. Bouzianea C, Caana MW, Tamminga HG et al (2018) ADHD and maturation of brain white matter: a DTI study in medication naive children and adults. Neurolmage Clin 17:53-59. https://doi.org/10.1016/j.nicl.2017.09.026

30. Dijkhuizen RM, Marel K, Otte WM et al (2012) Functional MRI and diffusion tensor imaging of brain reorganization after experimental stroke. Trans Stroke Res 3(1):36-43. https://doi.org/10.1007/s12975-011-0143-8

31. Farone S, Larrson N (2019) Genetics of attention deficit hyperactivity disorder. Mol Psychiatry 24(4):562-575. https://doi.org/10.1038/s41380-0180070-0

\section{Publisher's Note}

Springer Nature remains neutral with regard to jurisdictional claims in published maps and institutional affiliations.

\section{Submit your manuscript to a SpringerOpen ${ }^{\bullet}$ journal and benefit from:}

- Convenient online submission

- Rigorous peer review

- Open access: articles freely available online

- High visibility within the field

- Retaining the copyright to your article

Submit your next manuscript at $>$ springeropen.com 